\title{
TEXTO DIGITAL
}

Revista de Literatura, Linguística e Artes

\section{"Por um feminismo que queima cuecas": um estudo semiolinguístico da crítica teatral digital}

\author{
"For a feminism that burns men's underwear": a semiolinguistic study \\ of digital theatrical critics
}

\section{Mariana Pinter Chaves ${ }^{\mathrm{a}}$; Vanessa Maia Barbosa de Paiva ${ }^{\mathrm{b}}$; Priscila Natany Resende ${ }^{\mathrm{c}}$}

a Universidade Federal do Espírito Santo, Brasil - marianapinter@gmail.com

b Universidade Federal de São João del-Rei, Brasil - vanesssamaia@gmail.com

c Universidade Federal de São João del-Rei, Brasil - priscilanatany@yahoo.com.br

Palavras-chave: Crítica Teatral. Semiolinguística. Ciberespaço.

Sociedade Em Rede. Sujeito.

\section{Keywords:}

Theatrical Criticism. Semiolinguistics. Cyberspace. Network Society. Subject.
Resumo: Este trabalho tem o objetivo de analisar o contrato comunicacional de uma crítica teatral digital. Para tanto, partimos de postulações da Teoria Semiolinguística, principalmente das noções de sujeitos da linguagem e estratégias enunciativas presentes em Charaudeau (2001 [1984], 2005 [1983] e 2015 [1983; 1992]). O texto conta ainda com pensadores sobre a crítica teatral, tais como Garcia (2004) e Small (2015), bem como de teóricos que refletem sobre as modificações comunicacionais advindas das novas tecnologias, como Lévy (1999) e Castells (2000). Por meio da análise apreendida foi possível constatar que os sujeitos produzem atos de linguagem operando no nicho dos profissionais do teatro e da escrita crítica, do público teatral e de estudiosos ou interessados dessas duas áreas. A conclusão é de que o sujeito comunicante do corpus em estudo se apresenta como gatewatcher (BRUNS, 2003) e como uma enunciadora compreendida como uma crítica teatral ignorante (SMALL, 2015), por comunicar para todo tipo de público.

Abstract: This paper aims to analyze the communicational contract of a digital theatrical criticism. In order to achieve this, we start with postulates from the Semiolinguistic Theory, mainly the notions of Subjects of language and enunciative strategies presents in Charaudeau (2001 [1984, 2005 [1983] and 2015 [1983]). We also avail ourselves of thinker of theatrical criticism, such as Garcia (2004) and Small (2015), as well as theorists which reflect about the communication modifications brought by new technologies, such as Lévy (1999) and Castells (2000). Through the undertaken analysis, it was possible for us to verify that the subjects produce language acts operating in the niche of the professionals of the theater and of the critical writing, in the theatrical public, and in students or inquisitors by these two areas. We accomplish that the communicant subject from the corpus under study presents itself as a gatewatcher (BRUNS, 2003) and that the enunciator of the investigated digital text is understood as an ignorant theatrical critic (SMALL, 2015). 


\section{CONSIDERAÇÕES INICIAIS}

A revolução digital e a globalização foram responsáveis por transformações tanto dos movimentos artísticos quanto do pensamento crítico. Como consequência do surgimento das novas tecnologias, deparamo-nos com um recente espaço: o cibernético. Tal ambiente, por sua vez, faz emergir maneiras comunicacionais específicas, suscitando possibilidades investigativas.

De acordo com Garcia (2004), a crítica teatral tem um estatuto próprio e, estando ela agora na internet, interessou-nos verificar qual estatuto ela teria nesse lugar. Dessa forma, selecionamos, como corpus para o presente trabalho, a crítica Por um feminismo que queima cuecas escrita por Júlia Guimarães no dia 30 de janeiro de 2016 e publicada no site Horizonte da Cena.

Partindo dessas ponderações, nossa proposta é realizar uma análise sociointeracional, ancorada na Teoria Semiolinguística (doravante TS), tendo como base esse texto do site Horizonte da Cena. Para tanto, foi preciso delinear os sujeitos desse ato de linguagem, bem como as estratégias que eles utilizam, além de examinar seus componentes situacional, psicossocial e interacional, de modo a compreender como se dá o contrato comunicacional da crítica teatral digital.

Dessa forma, respaldamo-nos teoricamente em Charaudeau (2001; 2005; 2014), Lysardo-Dias (2010), Machado (2006) e Silva (2013) no que tange aos estudos Semiolinguísticos. Ainda, Garcia (2004), Gonçalves (2005), Michalksi (1984), Serelle (2012) e Small (2015) auxiliaram nossas reflexões teóricas acerca da crítica teatral. Valemo-nos, por fim, de Lévy, (1999), Castells (2000), Bruns (2003) e Christofoletti; Laux, (2008) para referendarem nossa proposta investigativa a respeito das modificações subjetivas e sociais advindas da comunicação através da virtualização.

\section{APORTE TEÓRICO}

Com o surgimento das novas tecnologias, passamos por uma revolução digital, na qual as mudanças nos meios de produção e recepção de conteúdos são responsáveis por aquilo que Christofoletti e Laux (2008) alcunharam de virada no mapa comunicacional. A ascensão da 
internet resulta em uma cultura que desponta com características próprias, nomeadas por Lévy (1999) de cibercultura. A comunicação mediada pelos computadores caracteriza, para Castells (2000), a sociedade em rede.

De acordo com Christofoletti e Laux (2008), a virada consiste na mudança de modelo da dinâmica social. Os autores explicam que, antes da ascensão da internet e das novas mídias, o modelo tradicional de comunicação era baseado na lógica de poucos para muitos, porém, agora, o formato passou a ser de muitos para muitos. No entender dos autores, a via comunicacional atual tem várias mãos e elas são duplas: muitas pessoas produzem conteúdos e informações por um lado, ao mesmo tempo em que muitas pessoas consomem os conteúdos e informações por outro e vice-versa.

Após a universalização do uso de rede de computadores, a cibercultura possibilitou uma comunicação ágil e imediata dos indivíduos sem importar o lugar onde se encontram. Lévy (1999) formula esse termo numa tentativa de explicar as novas expressões culturais como um “[...] conjunto de técnicas (materiais e intelectuais), de práticas, de atitudes, de modos de pensamento e de valores que se desenvolvem juntamente com o crescimento do ciberespaço." (LÉVY, 1999, p.17) Para o autor, há, agora, um entrelaçamento entre o mundo real e o mundo virtual, pois as discussões existentes no campo da internet afetam nosso cotidiano, ao mesmo tempo em que os temas do nosso dia a dia vão ser debatidos na internet. Por isso, ele afirma que a cultura produzida na internet é universal, uma vez que há interconexão entre todos os seres sociais. O termo ciberespaço, por sua vez, é entendido como esse novo lugar comunicacional no qual os indivíduos passaram a poder se comunicar, independentemente da distância que se encontram. De acordo com Lévy (1999), o ciberespaço não remete apenas à infraestrutura material da comunicação de rede, mas também a todo o universo de infinitas informações que ele possui e aos internautas que o constituem. Segundo ele, esse ambiente não é mais concreto, localizado em um território fixo, implicando, assim, uma nova relação de tempo e espaço. Tal conceito representa o surgimento de um universo que se distingue de "todas as formas culturais que vieram antes dele no sentido de que ele se constrói sobre a indeterminação de um sentido global”. (LÉVY, 1999, p. 15)

As relações dos indivíduos conectados vão configurando, para Castells (2000), sociedades em rede a partir das décadas de 1960 e 1970 quando, devido às ferramentas tecnológicas, a sociedade, a cultura e a economia começam a ficar interligadas. Segundo o sociólogo, as 
fronteiras vão diluindo e a cultura vai se tornando cada vez mais descentralizada. Nesse contexto, ele explica que a audiência para o conteúdo é diferenciada, pois o modelo clássico de comunicação atingia um grande público ao mesmo tempo; já a internet baseia suas relações em nichos. Dessa forma, Castells (2000) argumenta não ser mais possível usar o termo audiência para se referir ao material que está na internet, uma vez que o objetivo comunicacional é atingir comunidades específicas que se interessam por um determinado material. Ele defende que é o envolvimento do público com a produção cultural que transforma a audiência nas comunidades, por isso, podemos afirmar, com respaldo em Bruns (2003), que surge a figura do gatewatcher, com a finalidade de difundir os conteúdos e formar opiniões na internet. O gatewatcher é importante para a sociedade em rede e para a cibercultura porque é um agente que promove o debate público. Para Bruns (2003), essa figura é alguém reconhecido em determinado nicho, que atua em micro espaços de poder e que tem a capacidade de fazer com que os assuntos sejam compartilhados, gerando discussões na internet.

Diante desse cenário híbrido, o pensamento crítico também encontra-se em um contexto renovado. Small (2015) entende que a situação atual da crítica teatral é a de uma força emancipadora, pois desenvolve múltiplos olhares e novos tipos de interação entre espetáculo, público e mídia. Tal emancipação ocorre, conforme elucida a autora, devido à crise que a crítica teatral vivenciou com a perda de espaço nos veículos tradicionais de comunicação.

Em uma retomada histórica, Garcia (2004) esclarece que a crítica começa na imprensa brasileira pelas áreas artísticas tradicionais: literatura, música, teatro e artes plásticas. Ela afirma que as primeiras notas sobre teatro aparecem nos jornais com mais frequência quando estes passam também a adquirir maior consistência como veículos de comunicação, na segunda metade do século XIX. A partir de 1940, junto com o que se convencionou chamar de moderno teatro brasileiro, a autora explica que a crítica passa por um momento de ascensão, sendo escrita com profundidade. De acordo com ela, a geração de críticos

[...] que fazia parte orgânica do movimento teatral (autores, encenadores, produtores, cenógrafos) ou da universidade (professores e pesquisadores), manteve uma crítica militante, mais ou menos constante, e sempre muito comprometida com o desenvolvimento de um genuíno teatro brasileiro. Essa primeira geração atuou até os anos 1960 , quando uma nova safra de críticos ocupou as páginas dos jornais para falar de um teatro polêmico e contestador que tomou conta dos nossos palcos até o final dos anos 1970. (GARCIA, 2004, p.69-70) 
De 1980 em diante, a autora explica que a crítica de teatro no jornalismo diário passa a acompanhar o ritmo da indústria cultural e a se caracterizar por um estilo mais ágil, rapidez notada também nas montagens teatrais. Assim, Garcia (2004) defende que a crítica teatral é inerente à cultura dramática.

Para Serelle (2012) a crítica moderna da década de XX se estabeleceu como farol orientador para o público, a fim de nortear a opinião e educar os gostos, situando a obra de arte em seu contexto, à luz de movimentos e artistas que a antecederam. Por isso, ele afirma que as análises eram retrospectivas e prospectivas, pois, ao mesmo tempo em que atentavam-se às perspectivas antecedentes e tons genéricos, buscando condições sociais, estéticas e psicológicas que motivavam a produção artística, oferecia uma chave de sentido para sua compreensão. $\mathrm{O}$ autor também apresenta duas funções para a crítica: a judiciativa, que deveria avaliar a obra de arte a partir de certa grade de valores estáveis e a interpretativa, que partia da noção da obra como objeto complexo e lacunar, para obter dela sentidos, formulados numa escrita da compreensão mediadora entre arte e público.

Heliodora (1994 apud Garcia, 2004) considerava que a função da crítica seria dupla: por um lado ela serve ao artista, comunicando a ele até que ponto sua obra chegou ao público; e, por outro lado, faz ao público uma leitura do espetáculo e informa a respeito da obra. Prado (1987 apud Garcia, 2004) entende que a tarefa do crítico é, antes, de construir uma consciência teatral, de analisar e desconstruir o espetáculo, estabelecendo um diálogo com público e artistas para "conversar" sobre o sentido da peça, do que propriamente julgar se a obra seria boa ou ruim. Já para Banu (1995 apud Garcia, 2004) não existe um modelo crítico, mas críticos, e não há uma verdadeira crítica, e sim uma interrogação sobre a melhor maneira individual de situar-se e falar desta vida em segundo grau que é a vida do teatro.

Após o contexto da decadente perda de espaço na mídia tradicional, os profissionais que trabalhavam com jornalismo cultural e dedicavam-se à atividade da crítica passaram a usar as ferramentas das novas tecnologias para publicar seus textos e repensar a escrita da crítica para o espaço virtual. Consoante Lévy (1999) o movimento de virtualização é geral e afeta não apenas a informação e a comunicação, mas também os corpos, o funcionamento econômico, os quadros coletivos da sensibilidade e o exercício da inteligência. Para ele, a virtualização atinge 
[...] mesmo as modalidades do estar junto, a constituição do "nós": comunidades virtuais, empresas virtuais, democracia virtual... Embora a digitalização das mensagens e a extensão do ciberespaço desempenhem um papel capital na manutenção em curso, trata-se de uma onda de fundo que ultrapassa amplamente a informatização [...] a virtualização constitui justamente a essência, ou a ponta fina, da mutação em curso. Enquanto tal, a virtualização não é nem boa, nem má, nem neutra. Ela se apresenta como o movimento mesmo do "devir outro" - ou heterogênese - do humano. (LÉVY, 1999. p.11-12)

De acordo com Small (2015), as extensões cada vez mais curtas e restritas aos jornais e revistas possibilitaram à crítica teatral um espaço privilegiado na internet: de reação e de produção. Ela explica que, com a popularização dos meios digitais, esse universo veio se ampliando, possibilitando uma nova postura de quem trabalha com a análise crítica, bem como novos debates sobre a cena teatral.

Garcia (2004) explica que a relação do teatro com a imprensa sempre foi profícua, pois desde os seus primórdios o teatro esteve ligado ao jornalismo - que divulgava os espetáculos e servia de suporte para as críticas - por isso, esse gênero encontra-se inserido no meio jornalístico, caracterizado por ser um discurso sobre uma obra de cultura. Em consonância com a autora, Michalski (1984) defende que uma crítica sólida, competente e assumidamente opinativa e analítica é uma aliada importante do teatro, em qualquer época e lugar: ela cria em torno dele um clima de polêmica e discussão vital para o seu desenvolvimento, e contribui para formar no público uma curiosidade e um grau de exigência que, a longo prazo, resultam saudáveis para as artes cênicas. Garcia (2004) afirma ainda que a crítica teatral tem um estatuto próprio e que são muitas as opiniões sobre qual seria esse estatuto. Ela traz as definições de dois dicionários de teatro: o de Vasconcellos (1987), que aponta a crítica como uma discussão em torno de um fato estético, objetivando sua análise e interpretação, e o de Pavis (1999), que define a crítica dramática como um tipo de crítica geralmente feita por jornalistas, com o objetivo de reagir imediatamente diante de uma encenação e dar conta dela nos meios de comunicação, apontando quais espetáculos podemos/devemos ver.

Nos estudos da linguagem, mais precisamente na perspectiva Semiolinguística de Análise do Discurso, esse estatuto é compreendido como contrato de comunicação, que abarca um ato de linguagem específico. Devido ao fato de a TS ser uma abordagem que se nutre de diferentes campos teóricos e diferentes reflexões já empreendidas em torno da linguagem (LYSARDODIAS, 2010, p. 162), ela possui suas próprias concepções das noções de linguagem, discurso e texto. 
Patrick Charaudeau, fundador dessa teoria, entende a linguagem como um fenômeno complexo, que possui dimensões cognitivas, sociais, psicossociais e semióticas, correspondendo a um quadro semiológico, a um "[...] um conjunto estruturado de signos formais". (CHARAUDEAU, 2001, p. 24) O discurso é o objeto central dos estudos e está inserido numa problemática que relaciona os fatos da linguagem, “[...] sendo uns mais externos (lógica das ações e influência social), outros mais internos (construção do sentido e construção do texto)" (CHARAUDEAU, 2005, p. 13) a fenômenos psicológicos e sociais para desenvolver seus estudos ${ }^{1}$. Dessa forma, podemos afirmar que o teórico define discurso, de modo geral, como o lugar da encenação da significação. Para diferenciá-lo da noção de texto, questão que abarca uma confusão recorrente nos estudos linguísticos, o autor define texto, por sua vez, como "objeto que representa a materialização da encenação do ato de linguagem" (CHARAUDEAU, 2001, p. 25).

Em sua teorização, Charaudeau defende que o sentido do discurso depende das circunstâncias da enunciação e dos destinatários aos quais ele é dirigido. Em outras palavras, a TS objetiva tratar do fenômeno da construção psico-socio-linguageira do sentido, realizado por meio da intervenção de um sujeito também psico-socio-linguageiro, ou seja, ela busca compreender a construção do “[...] processo de semiotização do mundo". (CHARAUDEAU, 2005, p. 11).

O contrato de comunicação está na base da teorização semiolinguística e é um termo advindo do vocabulário jurídico-administrativo, remetendo a um acordo entre partes (MACHADO, 2006). Segundo Lysardo-Dias (2010), essa noção possui um potencial explicativo e analítico entre o que é e o que está pré-determinado como condição histórica e social de interlocução e as possíveis escolhas pessoais que os sujeitos realizam. A esse respeito Silva (2013) afirma que é por causa do contrato de comunicação que nós não falamos qualquer coisa para qualquer pessoa em qualquer lugar, uma vez que ele impõe limites para o que podemos e devemos falar.

Charaudeau (2001) delimita três componentes do contrato, relacionados diretamente a questões mais ou menos objetivas, uma vez que o que está presente, ao comunicarmo-nos é um jogo de interação, criando expectativas de interação entre os sujeitos. Como primeiro

1 Tem-se daí o caráter "antropofágico" da Semiolinguística, por reunir várias outras teorias. Tal termo é utilizado pelo próprio Charaudeau em suas conferências, conforme lembram Machado (2006) e Lysardo-Dias (2010). 
componente do contrato tem-se o comunicacional, entendido como o quadro físico da situação interacional. O segundo, psicossocial, é concebido em termos de estatutos que os parceiros são suscetíveis de reconhecer um no outro. Por fim, o componente intencional é concebido como um conhecimento a priori que cada um dos parceiros possui (ou constrói para si mesmo) sobre o outro, de forma imaginária, fazendo apelo a saberes supostamente partilhados.

O contrato sinaliza que o ato de linguagem, comumente chamado de situação de comunicação - realizado em um tempo e espaço determinados -, está submetido e, de alguma forma, regido por uma externalidade (LYSARDO-DIAS, 2010). Por isso, todo ato de linguagem está inserido em um contrato de comunicação estabelecido entre os parceiros (MACHADO, 2006). Os sujeitos comunicantes, na semiolinguística, encontram-se desdobrados em quatro instâncias subjetivas e dispostos em um quadro enunciativo, conforme a seguir:

Fig. 1 - Quadro enunciativo semiolinguístico

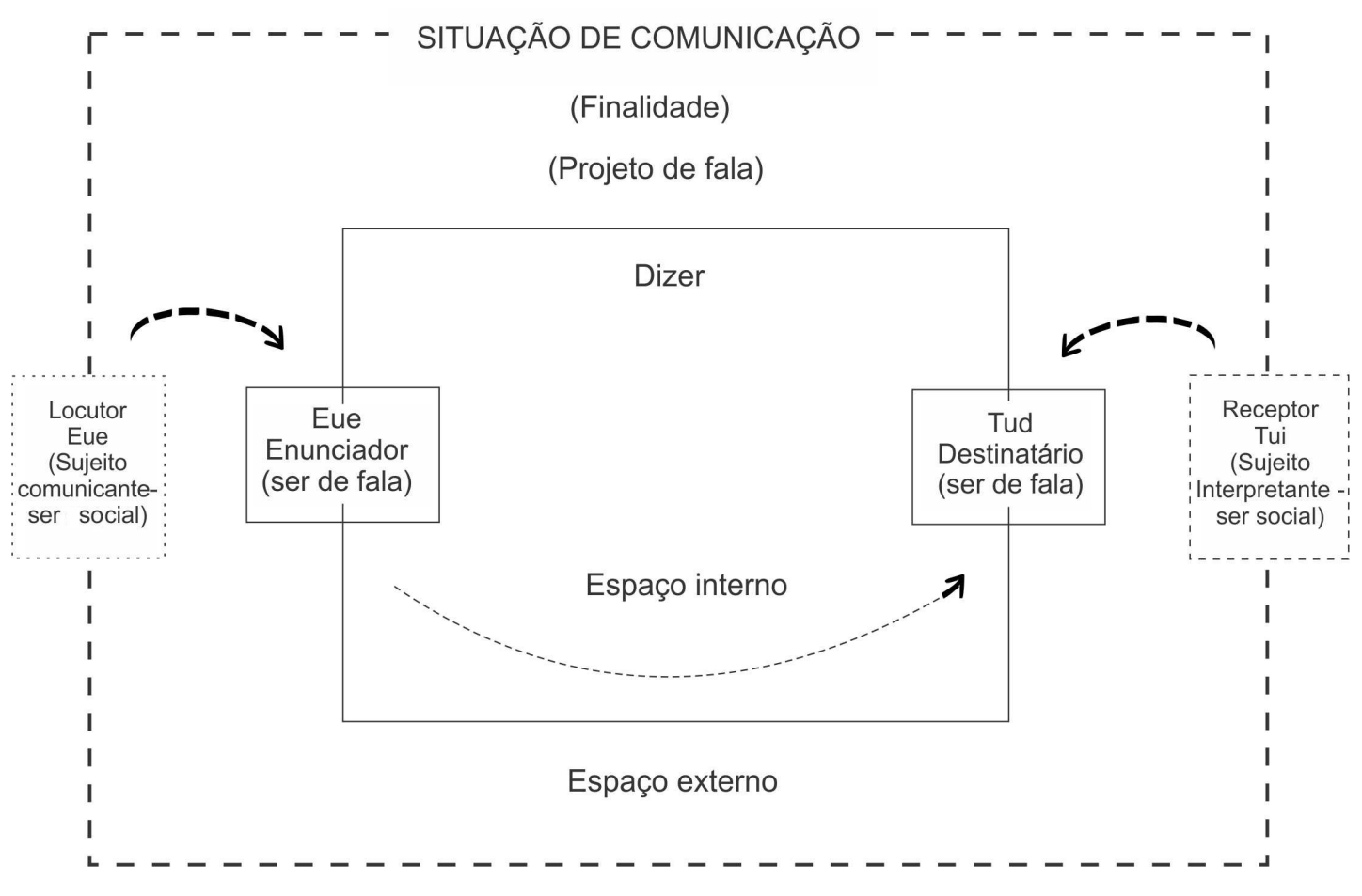

Fonte: Charaudeau (2014, p. 52)

De acordo com Lysardo-Dias (2010), dentre todos os dispositivos teórico-analíticos da TS, talvez um dos mais utilizados e testados seja a sistematização subjetiva esboçada neste quadro, por dar conta, concomitantemente, tanto da dinâmica dos atos de linguagem quanto dos seres sociais que atuam nas interações verbais. O sujeito que comunica "se lança em direção ao outro" (LYSARDO-DIAS, 2010) devido ao fato do ato ser uma proposição que o 
EU faz ao TU e sobre o qual ele espera uma contrapartida de conivência. Porém, o ato é encarado como uma aventura, pois, mesmo que haja um caráter intencional, de acordo com Lysardo-Dias (2010), o sujeito comunicante pode dominar somente a produção do enunciado, nunca os efeitos de sentido que este terá sobre seu interpretante. Para que essa expedição seja bem sucedida, Charaudeau (2014) afirma que o sujeito comunicante faz uso de contratos de comunicação e de estratégias e que os sentidos produzidos no texto serão, "[...] ao mesmo tempo sobredeterminados pelas restrições da situação de troca, e singulares pela especificidade do projeto de fala.”. (CHARAUDEAU, 2005, p. 19).

Charaudeau (2001) considera dois espaços em seu quadro enunciativo: o externo, situacional, do fazer e o interno, discursivo, do dizer, de maneira indissociável, uma vez que eles têm como característica estarem intercondicionados. Esses espaços estão diretamente relacionados às restrições externas sofridas pelos seres sociais e às estratégias internas possibilitadas pelos seres de fala. Lysardo-Dias (2010) afirma que, se os interlocutores estão, por um lado, subordinados a convenções, ideias ou imagens socialmente estabelecidas e difundidas, por outro, eles dispõem de um espaço, por menor que seja, de individualização por meio do qual deixam as suas marcas de sujeito único.

O semiolinguista explica que essas estratégias são múltiplas, mas que podem ser agrupadas em três, correspondentes aos tipos de condição para a encenação discursiva. O teórico define que a estratégia repousa na hipótese de que o sujeito comunicante concebe, organiza e encena suas intenções de forma a produzir determinados efeitos - de persuasão (adesão racional) ou de sedução (adesão emocional) - sobre o sujeito interpretante. Na legitimidade o sujeito falante cria ou reforça o seu direito à palavra, na credibilidade o sujeito falante faz crer ao seu interlocutor que ele é digno de fé e na captação o sujeito falante faz com que o interlocutor dê sua adesão absoluta ao que ele diz.

\section{ANÁLISE DO CORPUS}

Criado em 2012, o site de crítica de teatro Horizonte da Cena (HC) está sob responsabilidade das jornalistas Luciana Romagnolli e Soraya Belusi. Ele foi concebido inicialmente como um blog, editado somente pelas duas, porém, em setembro de 2015 assumiu um novo contorno. O HC foi remodelado para o formato de site, agregando editores, como Daniel Toledo e diferentes colaboradores. 
Fig. 2 - Página inicial do site Horizonte da Cena

início quem somos contato a

\section{horizonte da cena|}

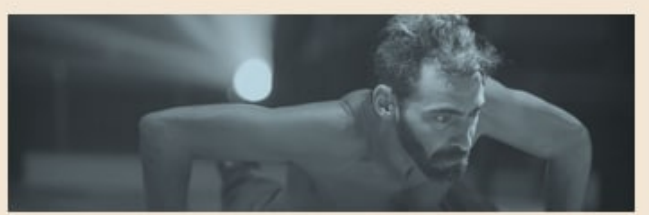

A investigação como princípio

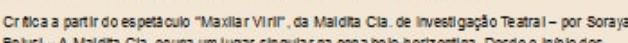

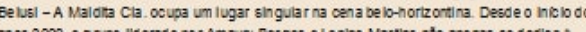
anos 2000, og rupo ilderado por Amaury Borges e Lenne Marths nto apenas se desloa encoborturas eriticas 295072016
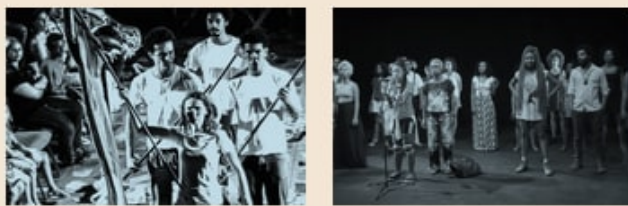

A unito o cos sujertos poiticos

Gr nos que esoanem nos

- por Luelana Romagnolll - Crrtica escrta a partir do espetasoulo "O Que Voce Tema ver Com 1560 ? da ZAP 18 (BM) Foto:

- por Danlel Toleso - Critica a partir das "Censs Pretas", conjunto forma 00 por " 0 o. 'to vazae pele", "Nbo conte comigo

am co borturas ertitcas 190712016

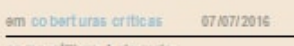

categorias

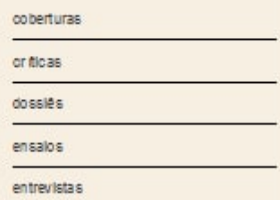

Fonte: ROMAGNOLLI; BELUSI (2017)

O Horizonte da Cena, por encontrar-se no ciberespaço, lança novos modos de expressão de pensamentos e de valores da crítica teatral, produzindo, dessa forma, cibercultura e um texto digital. Ele propicia que vários sujeitos estejam interligados, devido ao fato da diminuição das fronteiras que a sociedade em rede possibilita. Por meio desse recente mapa comunicacional, de deslocamento da crítica dos impressos para o digital, entendemos que a descentralização cultural baseia suas relações em nichos que, no caso de nosso corpus, são representadas pelas companhias teatrais, diretores, artistas, produtores, cenógrafos, iluminadores e toda a equipe técnica que possibilita que um espetáculo aconteça, bem como pelos críticos, jornalistas, pesquisadores, estudantes e público teatral.

Os sujeitos dessas comunidades específicas interessam-se pelas apreciações a respeito das artes cênicas, estabelecendo contratos comunicacionais com a finalidade de coconstruírem condições mínimas de entendimento do ato de linguagem crítica teatral. Essa relação contratual possui os seguintes componentes na crítica que analisamos: o quadro físico que compõe o comunicacional é o ciberespaço; os estatutos dos críticos, dos públicos e das 
companhias teatrais, a verificação psicossocial, variará conforme as relações de idade, gênero, etnia, dentre outros e corresponderá às questões culturais, sociais e históricas de cada um e, por fim, como componente intencional, verificamos que ele é mútuo. Afirmamos isso, pois há intenção mútua de influência: ao mesmo tempo em que o crítico teatral procura captar o leitor de seu nicho de atuação, o leitor internauta busca a leitura da análise teatral de acordo com sua vontade ou interesse. Além disso, esse leitor pode ainda expressar-se de maneira autônoma nos espaços destinados aos comentários sobre as impressões da leitura realizada, dispostos sempre abaixo das críticas no site, o que afirma o postulado de intencionalidade preconizado pela Semiolinguística, bem como o caráter interativo e dialogal de tal texto digital.

Na página da crítica teatral em estudo encontram-se, além das questões escritas relativas ao espetáculo Rosa Choque, a ficha técnica da peça, três fotos de Guto Muniz, que registram uma das apresentações desse espetáculo, e o mini currículo da escritora colaboradora. Temos, assim, em diálogo com a crítica teatral propriamente dita, outros textos verbais e imagéticos, possibilitados pela lógica do dispositivo cibernético, sendo possíveis de complementarem a interpretação do leitor.

De acordo com o quadro enunciativo postulado pela TS temos, em Por um feminismo que queime cuecas, instâncias subjetivas estabelecidas entre aqueles que se comunicam, por meio de uma relação contratual, tanto no âmbito de produção, quanto no de interpretação do texto digital. Dessa forma, o quadro enunciativo de nosso corpus seria o seguinte: 
Fig. 3 - Quadro enunciativo do texto de crítica teatral digital Por um feminismo que queima cuecas

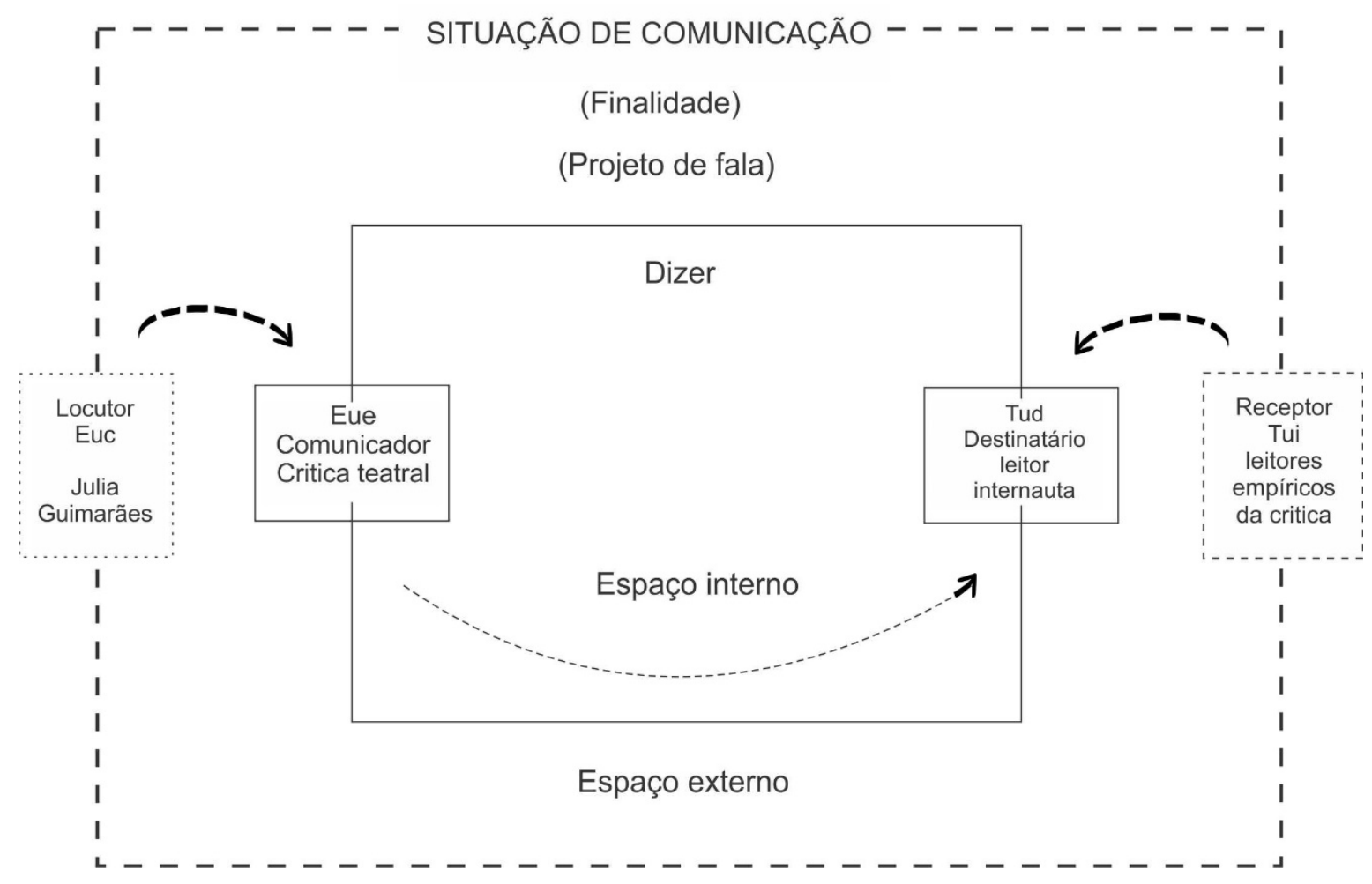

Fonte: Figura criada por Chaves; Natany; Maia (2017) com base no postulado semiolinguístico

Os sujeitos semiolinguísticos são parceiros ou protagonistas do ato de linguagem. Entre os parceiros, Charaudeau (2001) entende uma noção de fazer-valer recíproca em meio a pessoas que se reconhecem mutuamente, considerando-se dignas umas das outras. Já os protagonistas são "[...] um desdobramento do sujeito comunicante e do sujeito interpretante [...]" (LYSARDO-DIAS, 2010, p. 171), definidos por Charaudeau (2001) como seres de fala da encenação do dizer.

Na interação linguageira os parceiros são o sujeito comunicante (Euc) e o sujeito interpretante (Tui), implicados no jogo que lhes é proposto pela relação contratual. O Euc é o parceiro que detém a iniciativa no processo de produção, encenando o dizer e construindo hipóteses sobre o sujeito interpretante (Tui); por isso o resultado de sua atividade comunicativa produz efeitos de discurso possíveis. Essa instância subjetiva é assumida por Júlia Guimarães, ser empírico, “jornalista, crítica teatral e doutoranda em artes cênicas na Universidade de São Paulo (USP/Brasil)" (ROMAGNOLLI; BELUSI, 2017), com finalidade de analisar o espetáculo teatral Rosa Choque. 
O outro parceiro do ato, o Tui, é o sujeito que detém a iniciativa do processo de interpretação em função de suas experiências pessoais, isto é, suas próprias práticas significantes (que pode ser muda ou se exprimir por uma interação qualquer) com as hipóteses de saber que ele é levado a elaborar sobre o sujeito comunicante (Euc). Charaudeau (2014) explica que o Tui é um ser que age fora do ato de enunciação produzido pelo EU, só dependendo dele mesmo e se instituindo no instante exato em que opera um processo de interpretação.

O Tui de nosso corpus são os internautas que, de fato, leram a crítica, quantificados em mais de $340^{2}$ vistas pelo site. Como exemplo de sujeito interpretante, trazemos a explanação em destaque, conscientes que, ao se colocar por meio da escrita de um comentário, a instância subjetiva "Priscila Borges" acaba por assumir-se como Euc, uma vez que o comentário encontra-se regido por um outro contrato comunicacional, sendo, portanto, um outro texto.

Fig. 4 - Comentário de "Por um feminismo que queima cuecas"

\section{1 comentário}

Priscila Borges 1 ANO ATRÁs responder

Olá, sou Priscila e curso jornalismo. Assisti ao espetáculo na noite de ontem no teatro do Sesc e a obra mexeu muito comigo, não apenas por eu ser mulher na minha intimidade, mas por ser uma cidadã do gênero feminino, o que implica questões coletivas e não somente meus dilemas pessoais. Gostei muito desta análise, pois me elucidou ainda mais reflexões, só senti falta de comentar a sutileza da dramaturgia e de como o texto consegue agregar tantos contrastes.

Fonte: ROMAGNOLLI; BELUSI (2017)

É possível notar, neste enunciado, a utilização dos efeitos de persuasão “[...] elucidou ainda mais reflexões [...]" e de sedução “[...] a obra mexeu muito comigo". Depreendemos esses efeitos ao verificarmos que ela foi influenciada pela crítica, atingida pelos escritos, como no excerto "Gostei muito desta análise [...]" e, ainda, porque ela participa da regulação do jogo de influências dessa troca comunicativa, afirmando "só senti falta de comentar [...]". 
Os protagonistas do ato de linguagem são "[...] um desdobramento do sujeito comunicante e do sujeito interpretante [...]" (LYSARDO-DIAS, 2010, p. 171), definidos por Charaudeau (2001) como seres de fala da encenação do dizer, produzida pelo sujeito enunciador (Eue) e interpretada pelo sujeito destinatário (Tud). Tais seres assumem diferentes faces de acordo com os papeis que lhes são atribuídos pelos parceiros do ato de linguagem em função da relação contratual. O semiolinguista explica que o Eue é um ser de fala sempre presente no ato de linguagem, representando o traço de intencionalidade do Euc nesse âmbito de produção, é "[...] uma representação linguageira parcial de Euc. [...] é apenas uma máscara de discurso usada por Euc" (CHARAUDEAU, 2014, p. 49, grifo do autor). O outro protagonista do ato, Tud, por fim, é definido por Charaudeau (2014) como interlocutor fabricado pelo EU como destinatário ideal, adequado ao seu ato de enunciação. É preciso compreender a possível existência de vários Tud correspondendo a um mesmo ato de linguagem, ressalta Charaudeau (2014).

Por ser o parceiro que detém a iniciativa do processo de produção da encenação do dizer, entendemos que o Euc desta apreciação teatral possui legitimidade, produzindo efeitos de sentido possíveis, uma vez que, além de ser uma colaboradora convidada pelos editores do HC, Júlia Guimarães possui formação acadêmica na área teatral, informação reiterada por seu mini currículo situado à direita da sua crítica escrita, publicada no site. Ela atuaria, então, como uma gatewatcher no ciberespaço, como alguém reconhecido no nicho em que atua e que leva opiniões, possui um projeto de fala, promovendo debates na sociedade em rede.

O Eue de Por um feminismo que queima cuecas é a crítica teatral ${ }^{3}$, possuindo objetivo de propor uma discussão acerca da importância do teatro, por meio do tensionamento entre representação e ação, no combate ao machismo, principalmente aquele advindo dos homens. O próprio título já norteia para essa discussão, remetendo a uma cena do espetáculo que dialoga com a cena histórica icônica da queima dos sutiãs pelas feministas do século XX, nos Estados Unidos de 1968. Os atos de linguagem são construídos em sua escrita de modo a convencer o leitor de que as artes cênicas são um lugar privilegiado para autorreflexões teóricas, discursivas, performativas e micropolíticas. O sujeito enunciador persuade seu interlocutor que esse espetáculo em específico possui tratamento cênico condizente com a 
complexidade do feminismo; tanto o dos últimos séculos, quanto seus desdobramentos atuais no Brasil.

No entender de Small (2015), esse profissional precisa ser um crítico ignorante; ao contrário do crítico-juiz, que avalia se a obra é boa ou ruim, se deve ou não ser assistida. Aproximando-se do Mestre Ignorante, de Ranciére (2012), a autora defende que o crítico ignorante é aquele que não escreve para um leitor específico, para um "leitor médio", ele escreve para qualquer leitor. Nas suas palavras, a atividade desse escritor

[...] não pretende se tornar útil, adequada a uma situação de oferta e procura de espetáculos; ele não visa "prestar um serviço", quer apenas exercer a liberdade de dialogar com as obras, interpretá-las, conversar com a sensibilidade daqueles que partilham da admiração, da curiosidade ou da inquietação por estas obras. (SMALL, 2015. p. 103- 104, grifos da autora).

Percebemos que esta crítica teatral (Eue) é ignorante, pois escreve uma apreciação interpretativa, fazendo um exame retrospectivo e prospectivo ao mesmo tempo, atuando, como defende Serelle (2012), de maneira mediadora na compreensão dos sentidos entre os artistas e o público. Prova disso é que o Eue dialoga com o espetáculo de diversas formas, apontando questões sobre as quais esta obra lhe levou a refletir. A crítica situa que $O s$ conectores aborda a temática de desnaturalização de papeis historicamente definidos do homem e da mulher que culminam na geração de violências e privilégios, bem como as utilizações estratégicas de estranhamento e choque que a companhia utiliza ao aliar efeitos de real ao próprio teatro em momentos de ordem da experiência, sob uma perspectiva testemunhal. Ela escreve as "questões de fundo" que Rosa Choque traz como a repressão do corpo feminino, a redução do papel da mulher à maternidade, a culpabilização da mulher pela violência sofrida, o amor masculino como sinônimo de posse e o feminicídio. O sujeito enunciador escreve ainda sobre os recursos cênicos, os tratamentos dados aos personagens e as relações estabelecidas com o espectador, aliando suas argumentações às descrições das cenas, dos espaços, dos figurinos e dos personagens.

Somado a isso, essa crítica teatral enuncia para qualquer leitor, dialogando livremente com o espetáculo de Os conectores. Dessa forma, podemos afirmar que o sujeito enunciador possui credibilidade em sua escrita, porque mobiliza o reconhecimento de universos de saberes contidos neste ato de comunicação. Ela ainda utiliza-se da estratégia de captação ao julgar, por exemplo, alguns recursos que o espetáculo opera, tomando atitudes discursivas polêmicas 
ao dizer expressões como "pouco esclarecedora", "estranhamento menor" e "desfavorece seu potencial crítico".

No âmbito da interpretação do ato de linguagem e como o outro protagonista temos, como sujeito destinatário (Tud), ser de fala idealizado pelo EU, os leitores internautas. Podemos depreender que o Tud, por ser a instância "virtual" criada pelo Eue, seria formado por diferentes leitores desse nicho específico, citado anteriormente: profissionais do teatro, público teatral, profissionais da escrita crítica, estudiosos e curiosos dessas áreas. Vale lembrar a possibilidade de existência de vários sujeitos destinatários em um mesmo ato de linguagem.

\section{CONSIDERAÇÕES FINAIS}

A partir da análise feita, foi possível reconhecer que a crítica teatral digital escolhida como corpus analítico ocorre através do contrato estabelecido entre o(a) crítico(a) e o(a) leitor(a) internauta. Os atos de linguagem dessa enunciação utilizam-se de diferentes códigos semiológicos como fotografias, mini currículo, ficha técnica e comentário.

Em Por um feminismo que queima cuecas, averiguamos também que o sujeito comunicante (Euc) Júlia Guimarães apresenta-se como gatewatcher (BRUNS, 2003) devido ao fato de, em seu projeto de fala, atuar nesse nicho promovendo discussões e debates na sociedade em rede e por formar opiniões nesse micro espaço de poder. Evidenciamos ainda que o sujeito enunciador (Eue) crítica teatral é uma crítica ignorante (SMALL, 2015), pois ela escreve sua análise interpretativa com admiração, inquietação e curiosidade, sem pretender prestar somente um serviço de avaliação judiciativa do espetáculo.

Por fim, constatamos que as estratégias discursivas utilizadas pelos sujeitos no âmbito da produção linguageira (Euc e Eue) foram de legitimidade, credibilidade e captação. Embora tenha sido possível verificar em um sujeito interpretante (Tui), Priscila Borges, efeitos de sentido persuasivos (adesão racional) e seduzivos (adesão emocional), não podemos afirmar que os mesmos efeitos ocorreram sobre todos os leitores empíricos dessa crítica teatral. Não podemos delimitar também quais efeitos discursivos que essa leitura poderá proporcionar aos sujeitos destinatários (Tud) - profissionais do teatro e da escrita crítica, o público teatral e os estudiosos ou curiosos dessas duas áreas devido ao caráter de jogo/aventura de todo ato comunicativo que possibilitam apenas o apontamento de possíveis interpretativos. 


\section{REFERÊNCIAS}

BRUNS, A. Gatewatching, not gatekeeping: Collaborative online news. Media International Australia Incorporating Culture and Policy: quarterly 107 journal of media research and resources, 107, p. 31-44, 2003. Disponível em: <http://eprints.qut.edu.au/189/>. Acesso em: 20 out. 2014.

CASTELLS, M. A sociedade em Rede. São Paulo: Paz e Terra, 2000.

CHRISTOFOLETTI, R.; LAUX, A. P.F. Confiabilidade, credibilidade e reputação: no jornalismo e na blogosfera. Revista Brasileira de Ciências da Comunicação. São Paulo, v.31, n.1, p. 29-49, jan./jun. 2008.

CHARAUDEAU, P. Uma teoria os sujeitos da linguagem. In: MARI, H.; MACHADO, I. L.; MELLO, R. (Org.) Análise do discurso: fundamentos e práticas. Belo Horizonte: NADFALE-UFMG, 2001. p. 23-38.

. Uma análise semiolinguística do texto e do discurso. In: PAULIUKONIS, M. A. L.; GAVAZZI, S. (Org.). Da língua ao discurso: reflexões para o ensino. Rio de Janeiro: Lucerna, 2005. p. 11-27. Disponível em: http://www.patrick-charaudeau.com/Uma-analisesemiolinguistica-do.html. Acesso em: 28 mar.2017.

Linguagem e discurso: modos de organização. 2. ed. São Paulo: Contexto, 2014.

GARCIA, M. C. Reflexões sobre a crítica teatral nos jornais: Décio de Almeida Prado e o problema da apreciação da obra artística no jornalismo cultural. São Paulo: Mackenzie, 2004.

GONÇALVES, L. R. Os lugares da crítica da arte. São Paulo: Imprensa Oficial, 2005.

LÉVY, P. Cibercultura. São Paulo: Edições 34, 1999.

LYSARDO-DIAS, D. As contribuições de Patrick Charaudeau para o desenvolvimento da AD no Brasil. In: de PAULA, L.; STAFUZZA, G. (Org.). Da análise do discurso à análise do discurso do Brasil: três épocas histórico-analíticas. Uberlândia: EDUFU, 2010. p.161-180.

MACHADO, I. L. Algumas reflexões sobre a Teoria Semiolinguística. Revista Letras \& Letras, Uberlândia, v.22, n.2, p. 13-21, 2006.

MICHALKSI, Y. O declínio da crítica na imprensa brasileira. In: Cadernos de teatro do tablado. $100^{a}$ edição, jan/jun 1984. Disponível em

$<$ http://bancadetexto.blogspot.com/2010/01/o-declinio-da-critica-naimprensa.html >. Acesso em 05 ago. 2014. 
PAVIS, P. Dicionário de Teatro. São Paulo: Perspectiva, 1999.

RANCIÈRE, J. O mestre ignorante. Cinco lições sobre a emancipação intelectual. Belo Horizonte: Autêntica, 2012.

ROMAGNOLLI, L.; BELUSI, S. <www.horizontedacena.com.br>. Acesso em: 19. jan. 2017.

SERELLE, M. V. A crítica do entretenimento no jornalismo cultural. Revista Comunicação Midiática. Belo Horizonte: PUC-MG. v.7, n.2, p.47-62, maio/ago. 2012.

SILVA, J. O. Charaudeau. In: OLIVEIRA, L. A. (Org). Estudos do discurso: perspectivas teóricas. São Paulo: Parábola Editorial, 2013. p.235-260.

SMALL, D. A. O crítico ignorante. Rio de Janeiro: 7 Letras, 2015.

VASCONCELLOS, L. P. Dicionário de teatro. Porto Alegre: L\&PM Editores, 1987. 